\title{
Systemic Risk Analytics: A Data Driven Multi-Agent Financial Network (MAFN) Approach
}

\author{
Sheri M. Markose ${ }^{1}$ \\ Economics Department and Centre For Computational Finance and Economic Agents \\ (CCFEA), University of Essex, UK
}

\begin{abstract}
:
Systemic risk from financial intermediaries (FIs) refers to a negative externality problem which is rife with fallacy of composition type errors. To 'see' why seemingly rational behaviour at the level of an individual FI contributes to system wide instability is a nontrivial exercise which requires holistic visualization and modelling techniques. Paradox of volatility inherent to market price based measures of systemic risk has made bilateral balance sheet and off balance data between FIs and network analysis essential for systemic risk management. There is both a data and a skills gap in implementing large scale data driven multi-agent financial network (MAFN) models that can operationalize macro-prudential policy. Different designs for a Pigou type systemic risk surcharge are discussed with special reference to the Markose ${ }^{[1]}$ eigen-pair method which simultaneously determines the degree of instability of the network of financial flows of obligors and also the rank order in the centrality of FIs contributing to it.
\end{abstract}

JEL Classification Numbers: G01, G21, G17, G32, G15

Keywords: Systemic Risk; Macro-prudential policy; Financial Network; Agent based modelling; Eigenvector Centrality; Pigou type surcharge

\footnotetext{
${ }^{1}$ Sheri Markose is a Professor of Economics at the University of Essex and is also a Senior Consultant (2011-2014) at the Financial Stability Unit of the Reserve Bank of India. She was the founder Director (2002-2009) of the multi-disciplinary Centre for Computational Finance and Economic Agents which has pioneered a postgraduate curricula in Economics and Finance that uses agent based modelling and complexity economics.

This paper has benefitted from discussions with Alistair Milne, Rosa Lastra, Patrick McGuire, Teressa Glasser, Michael Bennett, Liz Dixon, David Bholat, Ulrich Krüger and other participants at the Future of Regulatory Data and Systemic Risk Analytics, Bank of England Workshop January 17-18, 2012. The author is grateful for inputs from anonymous referees and from Dalwinder Singh, the Editor of the journal. All views, errors and omissions are those of the author and cannot be attributed to any of the institutions mentioned above.
} 


\section{Introduction}

The 2007 financial crisis has undoubtedly exposed shortcomings of monetary and macroeconomics ${ }^{[2,3]}$ and of the regulatory framework of Basel II ${ }^{[4-7]}$. Macroeconomic models and their use in policy analysis have come under severe criticism. ${ }^{2}$ Critics have accused macroeconomists of heavy reliance on a particular class of macroeconomic models that has abstracted away institutional details and financial interconnections in the provision of liquidity, capital adequacy and solvency ${ }^{[8,9]}$. Consequently, the paradigm shift needed and skills gap that has to be fixed among academic economists and their regulatory counterparts is quite considerable in order to keep abreast of the institutional and technological innovations in monetary and financial sectors. These innovations have created at least three challenges:

(i) Unprecedented volumes of 'inside' money via securitization and other forms of procyclical collateralized private credit ${ }^{[10,11]}$;

(ii) A shrinking of state supplied cash in circulation in low cash based economies with an IT based payments technology which has changed payments habits and transactions demand for money irrevocably and also may have vitiated the monetary transmission of inflation in the CPI index ${ }^{[12,13]}$;

(iii) A vast interconnected system of digital transference of financial liquidity in real time with very low latency, along with 'algo' based hyper high frequency financial markets ${ }^{3}$, often leveraged by instruments such as contracts for differences.

I will argue that though the financial and monetary sources of systemic risk are myriad and protean as indicated above, placing regulators in a co-evolutionary arms race with regulatees [14], the fundamental and recurrent problem is how to maintain the stability of the intermediated financial and monetary superstructure which rests on a fractional base of fiat money. This world view had been eclipsed for decades due to the longstanding primacy of the rational representative agent in mainstream neoclassical economics ${ }^{[15,16]}$. A corollary of this was micro-prudential regulation of Basel I and II that focussed excessively on individual banking units, with no analysis or monitoring of the system wide consequences of activities of these units. In contrast, macro-prudential policy ${ }^{[17,18]}$ aims to safeguard the financial system as whole by mitigating systemic risk factors that can bring about system wide domino like failures of financial intermediaries (FIs) or destabilizing imbalances such as asset price bubbles that accumulate over time.

On the eve of the collapse of Lehman Brothers in September 2008 when the American Insurance Group (AIG) also stood imperilled due to its inability to make good on collateral calls for credit default swap (CDS) guarantees on mortgage backed securities of large FIs, a

\footnotetext{
${ }^{2}$ Buiter ${ }^{[2]}$ wrote "... the typical graduate macroeconomics and monetary economics training received at Anglo-American universities during the past 30 years or so, may have set back by decades serious investigations of aggregate economic behaviour and economic policy-relevant understanding." This view was echoed by Nobel Prize Winner Paul Krugman in the Economist, June 2010, "Most work in macro-economics in the past 30 years has been useless at best and harmful at worst."

${ }^{3}$ Foresight Report 2012: Available from: http://www.bis.gov.uk/assets/foresight/docs/computer-trading/12-1086-future-ofcomputer-trading-in-financial-markets-report.pdf.. This Report gives ample evidence for the challenges posed by the low latency environement in which algorithms rather than direct human are needed to execute trades.
} 
lack of data and models on the possible knock on effects in the US and globally, forced US Treasury and Federal Reserve officials to fly blind at the critical juncture. The moral hazard problem inherent to US, UK and European tax payer bailout of key FIs that ranged from full and partial nationalization to financial guarantees reached unprecedented amounts of over $\$ 14$ trillion, Alessandri and Haldane ${ }^{[19]}$, has aptly been called 'too interconnected to fail'. A prominent example of this was the US bailout package of $\$ 85$ bn for AIG which was geared toward averting substantial losses to its major counterparties. ${ }^{4}$

Post 2007, systemic risk from financial activities is being viewed as a negative externality analogous to environmental pollution ${ }^{[20,21]}$. In this case, over use and degradation of resources occurs as clean up costs are not internalized by the polluting economic agents due to a missing market. Likewise, over supply of leverage and excessive risk taking by financial agents follow because costs of their failure on others are not borne by them in the spirit of a Pigou tax ${ }^{[22]}$. The state of play in both the control of pollution and of financial leverage is that institutions have not yet been designed or evolved to adequately address the problem of aligning the interests of the individual actor and system wide stability. To 'see' why seemingly rational behaviour at the level of an individual FI contributes to system wide instability is a non-trivial exercise which requires holistic visualization and modelling techniques. Haldane ${ }^{[23]}$ has proposed the use of financial network models for the analysis of systemic risk from financial contagion that is driven by interconnected balance sheets. Clearly, the absence of such a quantitative modelling framework of the financial system has impeded progress in the monitoring and management of financial systemic risk.

The US Office of Financial Research was set up in 2012 to overcome problems of balkanization of financial and banking data and to have better models to provide quantitative oversight of the financial system nationally or globally. Institutions like the European Central Bank, International Monetary Fund and newly set up financial stability divisions in different countries with the Financial Stability Board (FSB) for international coordination have intensified efforts to develop modelling tools such as financial network analysis, ${ }^{5}$ 'big' financial data facilities ${ }^{[24]}$, which require Information and Communication Technology (ICT), and corresponding systemic risk analytics ${ }^{[25]}$.

Steps are now underway to design 'bail in' arrangements at the time of failure of FIs as part of resolution procedures ${ }^{[26,27] 6}$ and those that are paid for by FIs before failure to alleviate unacceptable socialization of losses from them. The focus of this paper is on the

\footnotetext{
${ }^{4}$ These include payouts to Goldman Sachs ( $\$ 14$ billion), Merrill Lynch ( $\left.\$ 6.2 \mathrm{bn}\right)$, Bank of America (\$0.8 bn) and Wachovia ( $\$ 1$ bn). Foreign banks were also beneficiaries. The major ones were Société Générale $(\$ 16.5 \mathrm{bn})$, Deutsche Bank $(\$ 8.5$ bn), UBS (\$3.8 bn), Barclays ( $\$ 1.5$ bn) and Royal Bank of Scotland ( $\$ 1.1$ bn). See, Table 22009 SIGTARP Report for this as well as on the bailout provisions for other AIG obligations such as $\$ 20$ bn commercial paper which had implications for the US money market mutual funds, http://online.wsj.com/public/resources/documents/aig111609.pdf.

${ }^{5}$ ECB 5 October 2009 Workshop on Recent Advances in Modelling Systemic Risk Using Network Analysis. Available from: http://www.ecb.europa.eu/pub/pdf/other/modellingsystemicrisk012010en.pdf?d216f976f3587224bcc087cc8149ed49, and also the IMF Workshop On Operationalizing Systemic Risk Monitoring 26-28 May 2010. Available from: http://www.imf.org/external/np/seminars/eng/2010/MCM/index.htm.
} 
second of these. The $\mathrm{FSB}^{6}$ has identified a list of global SIFIs and seek to impose capital surcharges on a sliding scale from $1 \%$ to $2.5 \%$ depending on factors such as large size, prominence in markets or functions (non-substitutability), complexity, global activity and interconnectedness. Will such generic surcharges help mitigate specific excesses such as the activities of SIFIs in derivatives markets? To answer this and other related questions, it is important to develop a framework to quantify the surcharges on FIs and to see whether they can mitigate the moral hazard problem entailed in tax payer bailouts.

Operationalizing systemic risk monitoring and management of FIs, at a minimum, needs to address the following: Is there a metric that can identify if financial intermediation is growing more unstable relative to Tier 1 capital in the system? Which FIs contribute to this instability and how does the failure of a FI result in domino losses in the ensuing financial contagion? How can a Pigou tax be shown to mitigate a FI's negative externality? Indeed, the efficacy of a systemic risk framework lies in whether it can help detect potential threats reminiscent of the AIG or Northern Rock debacle, viz. a combination of excessive build up of liabilities with growing interconnectedness with counterparties. These FIs in pursuit of privately rational objectives of market share and short term profits by aggressively borrowing in the interbank market and taking on large derivatives liabilities positions, respectively, became potential threats to the system. An important challenge for a macro-prudential regulator is that of curbing a FI's excessive activity in a sector using sectoral capital charges. ${ }^{7}$ Markose ${ }^{[1]}$ systemic risk framework, which will be discussed below, shows that the above FSB capital surcharges for global SIFIs are insufficient to cover the implicit socialized guarantees in place for the current level of their activities in derivatives markets.

The discussion in Section 2 will indicate the extent of the challenge for systemic risk management as financial leverage and lending take a plethora of forms which has intertwined banks with non-bank FIs and derivatives markets. The macro-prudential regulatory boundary is not one that can be predefined. It must co-evolve with developments on the ground. As the very size of the financial sector has real side negative consequences $^{[28]}$, the final objective of a macro-prudential model is to embed the financial sector model within a uses and sources flow of funds framework for the major economic sectors to monitor imbalances between the sectors. Section 3 of the paper will give a brief overview of the ICT based multi-agent financial network (MAFN) modelling tools that can build digital simulation platforms from fine grained firm level data bases to monitor and manage systemic risk from complex interconnectedness of market participants and potential perverse regulatory incentives that may exist. Agent technology can provide an antidote to the Lucas Critique that afflicts macro-econometric models in policy related

\footnotetext{
${ }^{6}$ FSB Progress Report on Resolution of SIFIs, November 2012. Available from: http://www.financialstabilityboard.org/publications/r_121031aa.pdf. See also, FSB Reducing the moral hazard posed by systemically important financial institutions. 2010 Oct 20. Available from: http://www.financialstabilityboard.org/publications/r_101111a.pdf.

${ }^{7}$ This challenging aspect of a systemic risk framework has been raised under items 14-16 of the Bank of England Record of Financial Committee Meeting (RFCM) held on 16 March 2012. Available from: http://www.bankofengland.co.uk/publications/Documents/records/fpc/pdf/2012/record1203.pdf.
} 
stress tests. Some insights into the relationship between network topology and financial contagion will also be given.

Section 4 discusses the design issues behind a metric for systemic risk as a negative externalities problem. Market price based systemic risk measures favoured by many economists, as it is based on publicly available data, are now recognized to be fraught with problems. A brief overview given in Section 4.1 of the so called paradox of volatility ${ }^{\text {[29] }}$ indicates that this detrimentally affects market price based statistical cross correlation models of financial contagion and systemic risk. This has meant that structural bilateral balance sheet and off balance sheet data based network models are needed to study systemic risk from financial interconnections.

Section 4.2 discusses how the financial network approach can deliver on systemic risk modelling. Since the classic Furfine ${ }^{[30]}$ stress tests that used financial balance sheet interlinkages to analyse financial contagion from the failure of a 'trigger' FI, a very large body of work using network analysis (see ${ }^{[1][31][32]}$ for recent reviews) has developed for systemic risk management. Here, though financial network models have provided great visual images of interconnectedness and some insights into how financial networks become fragile and propagate contagion, much of this literature has not yet delivered on a design of a systemic risk measure or a Pigou tax on the basis of a FI's balance sheet based interconnections, let alone a metric for network stability. Markose ${ }^{[1]}$ uses the insight from May ${ }^{[33,34]}$ that network stability depends on the size of the maximum eigenvalue of an appropriate dynamical characterization of the network system and a common threshold. It is operationally convenient to be able to express the network stability condition in terms of a threshold rate of the policy variable, viz. Tier 1 capital. This has led to the so called eigen-pair method in Markose ${ }^{[1]}$ in which there is a simultaneous determination of the maximum eigen-value of the networked system of bilateral liabilities of FIs adjusted for Tier 1 capital and the corresponding right eigen-vector centrality measure for who contributes to instability. These metrics based on actual bilateral financial obligations are simple to calculate and can be monitored over time. Finally, I discuss issues raised by ${ }^{[35]}$ in their survey on recently proposed systemic risk analytics, especially for the class of Pigovian capital surcharge. They note that the many ad hoc model related assumptions, calibrations and data manipulations, make it questionable whether FIs will or should be made to be liable for less than robustly derived capital surcharges. ${ }^{8}$ Section 5 gives some concluding remarks.

\section{Systemic Risk of Financial Systems: Old Problem, New Challenges}

\subsection{Fractions and Multipliers in Financial Intermediation}

At a substantive level, the main threat from private credit based liabilities is no different from well-known problems with fractional deposit banking. In both cases there is a potential for periodic collapse with knock on effects on several FIs and the real side of the

\footnotetext{
${ }^{8}$ Biasis et. al. ${ }^{[35]}$ cite the trade association Clearing House for 17 of the world's largest commercial banks on this: "there are significant open questions regarding the purported theoretical and policy foundations, as well as appropriate calibration, for a G-SIB surcharge".
} 
economy when en masse convertibility is triggered for more liquid forms of central bank regulated funds for which the tax payer remains liable. Since the days of Henry Thornton ${ }^{[36]}$, it has been known that circulating private credit in the form of commercial paper is discounted multiple times in the chains of rehypothecation, to use a neologism ${ }^{9}$, which has to be redeemed in sequence to avoid crashes. The most recent manifestation of this, though not recognized as such till after the 2007 crisis, came with the proliferation of securitized banking where the volume of non-depository short term funding is determined by 'haircuts' and rehypothecation of mortgage backed commercial paper as collateral in the repo markets ${ }^{[10,38]}$. This feature of capitalism remains both an essential conduit of funds as well as a potential threat to stability due to convertibility problems in the fractional system. The dominance of non-depository FIs in the loanable funds markets in many G10 countries which are subject to the same 'runs' as banks has meant there is no sense in regulating only banks for liquidity and capital requirements. The regulatory boundary needs to reflect the ever changing forms of collateralized liquidity creation.

While the history of monetary institutions and central banking is replete with attempts to 'cap ${ }^{10}$ or control both public and private debt creation to deal with the fractional nature of credit, the latter problem is now exacerbated in that it can be leveraged further using derivatives. A key aspect of recent innovations in private credit relationships is to rely on a complex set of interlinking obligations between a small number of FIs in terms of enhancements, guarantees and derivatives for risk sharing, ${ }^{[7,40,41]}$. Credit risk transfer from banks' balance sheets using credit derivatives also allows banks to replace capital by unfunded contingent claims. This was and continues to be the central plank, of Basel II and III ${ }^{[4,6,41]}$. At the level of the individual user these schemes appear plausible but at the macro-level they lead to systemically unsustainable outcomes. In view of the structural concentration in the provision of risk guarantees through financial derivatives, noted as early as Darby ${ }^{[42]}$, the topological fragility of the modern risk sharing institutions are germane to issues on systemic risk, Markose ${ }^{[1]}$.

There is the prospect that institutions ${ }^{11}$ may evolve that can overcome the above pervasive source of systemic risk from financial intermediation. However, in the meanwhile, the public good aspect of the financial system dictates comprehensive monitoring and regulation to overcome such market failures. For this, as envisaged in the extensive powers given to the newly established macro-prudential regulators in G-7 countries, nothing short of a paradigm shift has occurred.

\subsection{The Macro-prudential modelling challenge}

\footnotetext{
${ }^{9}$ I first encountered this in Singh and Aitken ${ }^{[37]}$. Rehypothecation refers to the reuse of the same collateral to obtain funds by different parties before its maturity.

${ }^{10}$ See, Milne ${ }^{[39]}$ (2013) for an interesting discussion on this. Stiglitz ${ }^{[3]}(\mathrm{pp} 603-609)$ has commented on this centuries long unsolved problem in capitalism.

${ }^{11}$ Electronic peer to peer (P2P) lending between ultimate end users and fund surplus units (see, The Economist Dec 15-21 2012) bypasses the dysfunctional fractional intermediating banking sector. Platforms facilitating P2P lending do not suffer maturity mismatch or 'runs' as in banks as P2P lenders cannot withdraw funds once they have been lent and can expect repayment at a fixed maturity date, Verstein ${ }^{[41](\mathrm{p} 466)}$. The electronic matching platform is an evolutionary development that is made feasible by the IT revolution. Note, the latter has facilitated the substitution away from state supplied notes and coins in economic transactions that Hayek ${ }^{[44]}$ had hypothesized as the only permanent way to end inflation. Of course, Hayek $^{[44]}$ did not anticipate the IT payment innovations such as EFTPOS and e-commerce that has vitiated the use of cash in transactions.
} 
Many now recognize that there was an aberration ${ }^{12}$ in mainstream monetary economics and central bank doctrines which led central bankers, in many a case by statute, to focus primarily on a fixed rule to do with inflation targeting ${ }^{[45,46]}$. The abrogation of responsibility by central banks over the credit creation mechanism came to the forefront in not seeing, respectively, the threat from shadow banking which had grown to $\$ 20$ Trillion in the US by $2008{ }^{\text {[47] }}$, and the increased lending using mortgage backed covered bonds by banks in the core to those in the periphery of the Eurozone to fuel a housing bubble ${ }^{[48]} .^{13}$ The transformation of the Phillips curve, unbeknownst to most macro-economists, manifests in the flat CPI price inflation-output trade off in low cash based G10 economies where inflation fell to around $2.5 \%$ by $1994^{[13]}$. This, along with the low volatility for market risk that characteristically accompanies asset bubbles, may have lulled monetary authorities into a state of complacency which has sometimes been dubbed Great Moderation ${ }^{[49]}$. This lack of inflationary overheating in low cash based economies, allows the use of the 'Greenspan put' and loose monetary policy with impunity to entrench asset price bubbles and structural imbalances. Disintermediation from real investment has meant that GDP growth becomes correlated with the growth of the financial sector and asset/commodity price bubbles, contributing to ever growing systemic risk. This has led many to regard the macro-prudential modelling challenge to entail the embedding of a highly disaggregated financial sector ${ }^{[50,51]}$ and as will be discussed below, in the case of agent based models, a the full electronic mapping of the financial system, within a sectoral uses and sources of funds framework to monitor growing macro-economic imbalances.

\section{Digital Mapping of the Financial System From Databases}

\subsection{A Multi-Agent Financial Network (MAFN) Model}

Recently, many have emphasized the uses of agent based computational economics (ACE) simulation platforms for digital mapping and monitoring of the financial system, stress testing and for institutional design (see ${ }^{[52-55,14]}$ ). These artificial environments can depict real time orientation, institutional rules, and also complex interactions. For the simulation framework to be useful for the assessment of policy, financial firm level responses must be modelled in the context of prevalent market and regulatory conditions and with automated access to balance sheet and off- balance sheet data of FIs to anchor their financial decisions.

From the vantage of $21^{\text {st }}$ century ICT based tools, a non-economist may be forgiven for painting the following picture of how regulators manage systemic risk problems in the

\footnotetext{
${ }^{12}$ Schularick and Taylor ${ }^{[11]}$, say that "it is a mishap of history that just at the time when credit mattered more than ever before, the reigning doctrine had sentenced it to playing no constructive role in monetary policy. In terms of policymakers and researchers history demonstrates that that they ignore credit at their peril."

${ }^{13}$ In the case of Spain, the fastest growing housing bubble, which outstripped the one in the US, was financed by French and German banks with the sale of mortgage backed covered bonds primarily by Spanish Cajas which grew from a mere Euro 50 billion in 2003 to over Euro 350 billion by 2007. See Table 1 in http://www.ecbc.eu/uploads/attachements/45/64/3.27\%20Spain.pdf. The website and reports are those of the European Covered Bonds Council of the European Mortgage Federation.

${ }^{14}$ Haldane's speech at the 2013 January BCBS Workshop ${ }^{[55]}$ described this as the Star Trek vision of a large electronic screen displaying financial data as an interconnected system.
} 
financial system. Mark Buchanan ${ }^{[52]}$ in a paper in Nature gives an account of what advanced IT based tools can deliver : "A screen on the wall maps the world's largest financial players - banks, governments and hedge funds - as well as the web of loans ... and other legal claims that link them. High-powered computers have been using these enormous volumes of data to run through scenarios that flush out unexpected risks. And this morning they have triggered an alarm.... Flashing orange alerts on the screen show that a cluster of US-based hedge funds has unknowingly taken large ownership positions in similar assets. If one of the funds should have to sell assets to raise cash, the computers warn, its action could drive down the assets' value and force others to start selling their own holdings in a self-amplifying downward spiral. Many of the funds could be bankrupt within 30 minutes, creating a threat to the entire financial system. Armed with this information, financial authorities step in to orchestrate a controlled elimination of the dangerous tangle." Needless to say, such web based visualization of financial data and real time operations relating to financial crisis management is far from being implemented. The fundamental computational methodology for web based visualization of complex data sets is object oriented programming (OOP) and multi-agent modelling. The technological ICT aids of the 'zoom' that can navigate between the coarse grained bird's eye view and the fine grained ones can mitigate the well known befuddling aspects of not being able to see 'the woods for the trees'. The 'probe' can automate and highlight behind the scenes hidden links of each FI in multiple markets. Unfortunately, such enabling technologies of advanced ICT economies have yet to be harnessed for economic analysis and systemic risk monitoring.

Agent based computational economics or ACE using the acronym coined by Leigh Tesfatsion ${ }^{[56,57]}$ is based on object oriented programming that can produce agents that are both inanimate (eg. repositories of data bases) as well as behavioural agents capable of varying degrees of computational intelligence. These range from fixed rules to fully adaptive agents representing real world entities (such as banks, consumers and regulators) in artificial computer environments which can be replicas of, for instance, the financial system. Unlike conventional programming in which a program entails a lists of tasks or subroutines, in ACE and OOP, each agent which is an instance of a class is capable of interacting with other agents by receiving and sending 'messages', processing data, and producing outputs on the basis of their computational intelligence. The outputs can be accessed by the experimenter and the agents themselves using 'probes'. There is considerable literature on ACE models that have produced qualitative insights into classic non-deducible self-organized outcomes. These range from the Schelling ${ }^{[58]}$ model on racial segregation to the Santa-Fe Institute stock market model of Arthur et. al. ${ }^{[59]}$ which showed the endogenous generation of boom bust cycles on account of the contrarian payoff structures in stock markets. Thurner et. al. ${ }^{[60]}$ give a recent example of how an agent based simulation model can show how leverage exacerbates boom bust cycles in an artificial stock market model. However, the empirical data resolution end of these ACE models is low for macro-prudential regulatory purposes.

In financial networks, nodes stand for financial agents such as banks, non-bank intermediaries, the final end users and central banks. The edges or connective links represent directed inflows (in degrees) of liquidity or receivables, and outflows (out degrees) represent 
obligations to make payments. By data base driven MAFNs is meant that disaggregated data at the level of individual FIs with regard to bilateral flows to each of their counterparties will have to be accessed electronically to provide 'as is' quantitative characteristics. Figure 1: Modelling of FIs and their Interconnections For Purposes of Macro-
Prudential Policy

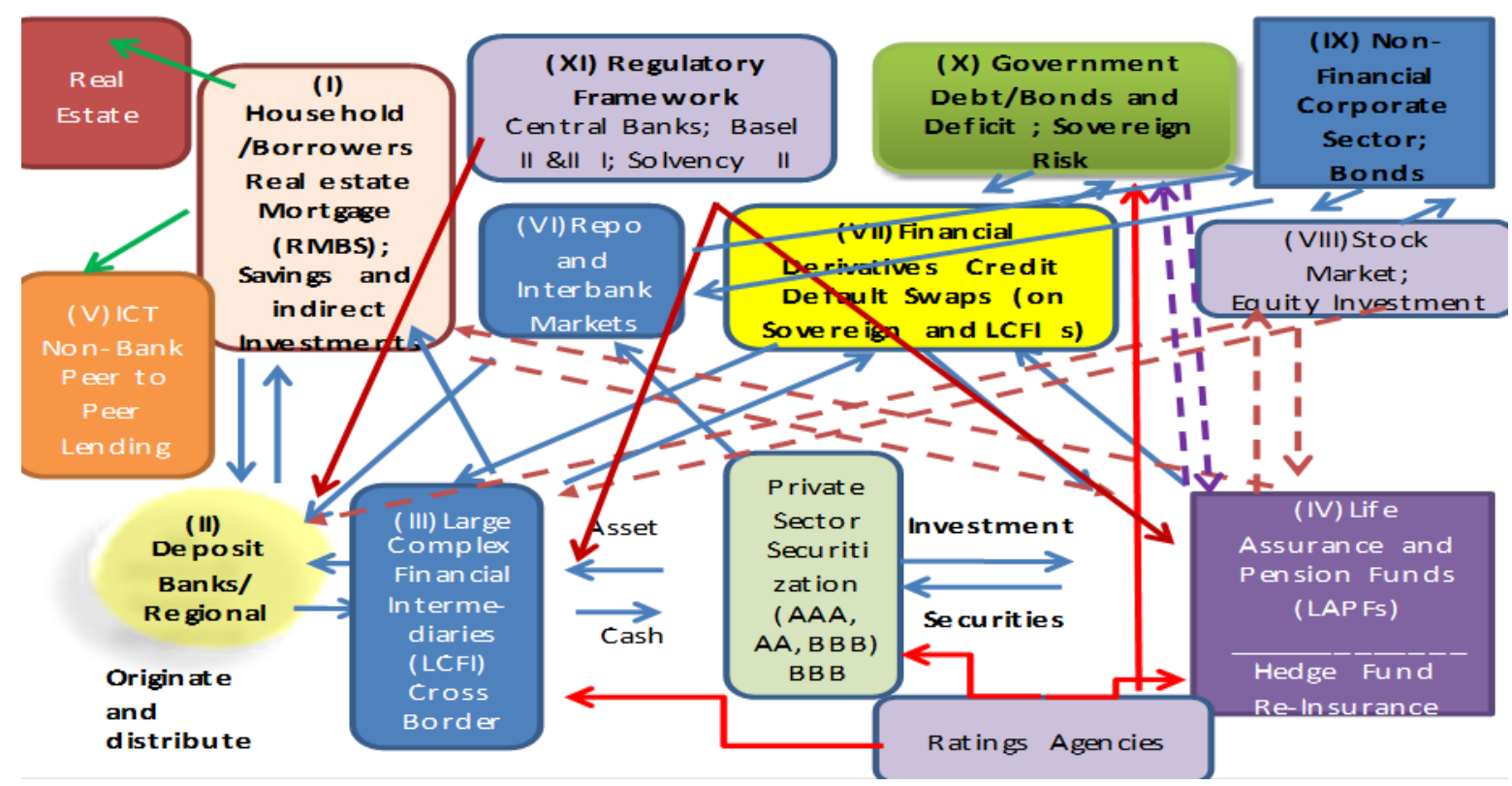

Figure 1 gives a stylized graph for the scope, discussed in section 2, of a MAFN model which incorporates the classes of financial agents (depository and non-depository FIs, items II, III, and IV), types of financial products/markets (RMBS, Repo, Derivatives, Sovereign Bonds, Equities, items I, VI, VII, VIII) and the complex interconnections between them (the arrows and item XI). The financial interconnections at a bilateral level for all depository and nondepository FIs can be embedded into a more aggregative framework for the sectoral uses and sources of funds involving the household sector, government, non-financial corporate sector, monetary and financial sector and global flows. The item (V) in Figure 1 on Peer-Peer lending indicates the need to include new financial sectors as they evolve.

In principle, each FI is a vector of financial activities operating in a multi-layer system of markets for different financial products, each of which has its own network topology, institutional incentives and constraints. This is illustrated in Figure 2. In the multi-layer networks in Figure 2 (RHS), the broken vertical lines show the FIs that are common to the different networks for financial products and hence they can become the conduit by which an exogenous shock in one market can be propagated across other markets. However, to date, 
most financial networks are modelled as single layer ones, either of a single market or one which represents aggregation of several products. Full scale developments of MAFN models as hyper-networks ${ }^{[61,62]}$ are only in their infancy. Nevertheless, for purposes of regulatory monitoring, as will be seen, even quarter by quarter snap shots of network visualizations and analytics of bilateral financial flows data whether for specific financial products or as a single layer network for flows aggregated over products, are useful to gauge instability of the system and of the centrality or systemic importance of FIs in it.

Figure 2 Single Layer Network (LHS) and Multi-Layer Networks (RHS)
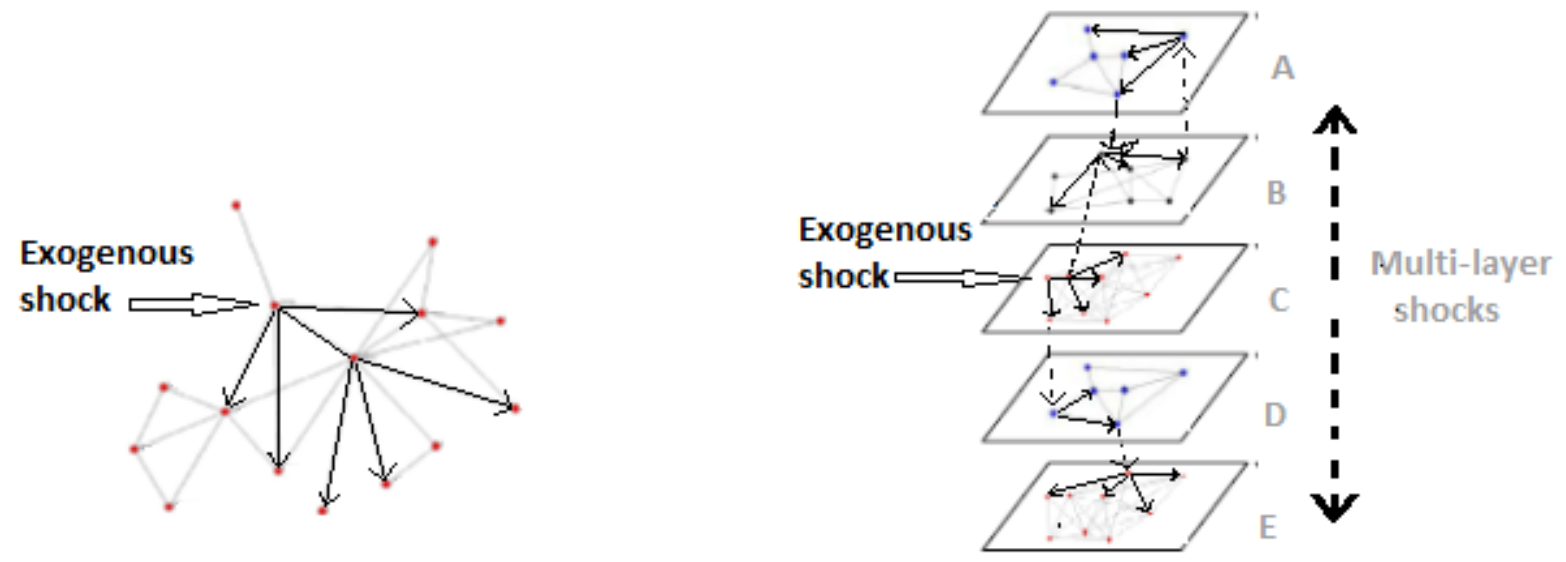

Integration and automation of financial data bases in a MAFN framework, therefore, aims to transform the data from a document or record view of the world to an object-centric view ${ }^{\text {[63] }}$ where multiple facts about the same real-world financial entity are accessed to give a composite visualization of their interactions with other such entities in a scalable way. Without powerful integrative tools for system wide visualization of firm level data pertaining to all sectors of the financial system, in an increasingly complex environment where size of nodes or parts of networks alter and new subnets form as new financial instruments come on stream, it will be hard to 'see' or quantify systemic risk impacts of units such as key brokerdealers, a sector such as a centralized clearing platform or a market for unfunded claims such as credit derivatives. As in the Buchanan's excerpt above, orange alerts can be assigned to threat factors such as overleveraged positions and the pro-cyclicality of underlying assets to the same macro-variable that include house prices or debt of a specific sovereign.

Till recently, the IBM MIDAS project ${ }^{[63,64]}$ and the EC grant FP6 -034270-2 project of Markose and Giansante currently being implemented at the Reserve Bank of India (see ACEfinmod.com) are the only known software technologies being developed for large scale 
firm level financial database driven models for systemic risk analysis. ${ }^{15}$ Since mid 2010, the Financial Stability Unit of the Reserve Bank of India has started mandating all depository institutions (including foreign banks operating in India) and a large majority of the nondepository FIs to submit bilateral financial data for non-electronically cleared products in the funded and unfunded derivatives markets. Central Banks of Brazil and Mexico are also mandating bilateral financial data from their FIs.

The EURACE project aims to develop a methodology for large scale data base driven multiagent macro-economic models for the Euro zone ${ }^{[65]}$. However, though some agent based exercises have been conducted with simulated data, the EURACE project has not produced any implementations of large scale data base driven agent based macro-economics models. The RAMSI (Risk Assessment Model for Systemic Risk Institutions) model of the Bank of England is based on the balance sheet data of the 10 core UK banks for 650 balance sheet entries. In the absence of bilateral data, the balance sheet bilateral interconnections are modelled using the Entropy maximization method, which as will be discussed is known to introduce model risk. Aikman et. al ${ }^{[66]}$ stress test the model for asset and liability side shocks which precipitate non-linear feedbacks like those that arise from deleveraging and fire sales. Calibrations are used to determine loss of capital from fire sales. The counterparty failures add to losses via the matrix of interbank exposures for the top UK banks. Banks are each assigned points on the basis of structural imbalances such as reliance on short term money markets, maturity mismatch etc and those that score points in excess of 35 are judged to be in the danger zone. The absence of off balance sheet items and non-bank FIs, clearly make the RAMSI model less than comprehensive for purposes of systemic risk monitoring. Further, the lack of a publicly available electronic data warehouse for quarterly data on the financial statements of depository institutions operating in the UK, let alone those for nondepository FIs, implies that there is some way to go before a MAFN model with the scope of Figure 1 can be developed for the UK even using empirical calibrations for reconstructing financial interconnections. ${ }^{16}$

Finally, how does ACE compare with estimation based macro-econometric models for policy analysis? In ACE, interactions of agents produce system wide dynamics that are not restricted to pre-specified equations which have to be estimated using past data in econometric or time series approaches. In ACE, each agent follows explicit rules or evolves strategies under specified market conditions and a 'probe' monitors causal internal workings and also aggregates outcomes. In contrast, the main draw-back of estimation based equation analyses is their susceptibility to the Lucas Critique in that structure changes from strategic behaviour and tracing of causal links are almost impossible to do. The idea that nodes in the network which constitute FIs and other financial actors are themselves intelligent 'agents' autonomously evolving strategies while operating within constraints and incentives provided

\footnotetext{
${ }^{15}$ This Special Issue contains developments in large scale financial data based modelling in different countries such as the US, Austria and others.

${ }^{16}$ The Bank of England Electronic Reporting Service (BEERS) obtains quarterly financial statements from all banks operating in the UK in an electronic format. However, the data is then aggregated to yield the balance sheet information for the Monetary and Financial Institutions Sector and also for the Table on Derivatives for all UK banks. Available from: http://www.bankofengland.co.uk/statistics/Pages/bankstats/2012/Dec12/default.aspx.
} 
by the markets and regulations has not been fully operationalized yet for purposes of policy design. ${ }^{17}$ In response to the riposte by many ${ }^{[6,69,70]}$ that a great source of systemic risk is perverse incentives from policy, viz, policy fails precisely when FIs comply with it, Markose et. al. ${ }^{[41]}$ give an exemplar on how this can be monitored on an ongoing basis using MAFNs. All FIs from the US FDIC Call Reports data set from 2003 onwards that were involved in credit default swaps were made to comply, by programming this in the ACE model, with the Basel II incentives in synthetic securitization to reduce capital from $8 \%$ to $1.6 \%$ by keeping RMBS assets on balance sheets and acquiring credit default swap guarantees. The build up of what became toxic RMBS assets on major US banks' balance sheets along with CDS purchases which were shown to belong to a topological unstable network structure, followed as if according to a gory script !

In agent based models, rule following behaviour as in complying with the regulation and the conduct of carry trade activity are relatively easy to implement. This is because unlike fully fledged adaptive behaviour, agents' strategies, intelligence and autonomy are limited to following the letter of the law and strictly verifying conditions for which the most profitable arbitrage applies. The modeller, however, faces the challenge of understanding the regulation, provide market conditions for the triggers that need to be followed in a carry trade and then implement the agents' strategies in an algorithm. Markose et. al. ${ }^{[41]}$ argue that as stress tests for perverse incentives of policy is among the easiest of MAFN exercises, it must be de rigueur in macro-prudential policy in order that flawed policies do not get perpetuated.

\subsection{Financial Network Topology and Propagation of Contagion : Network Topology Matters}

The reason why it is important to map the actual interconnections between FIs is because network topology is a major determinant in how contagion propagates and the system fails. Interventions and stabilization crucially depend on knowing who is linked to whom. In the absence of actual bilateral financial data, the bulk of the pre 2007 simulated financial network models assumed that they were random graphs or used the entropy maximization method for network formation which aims to maximize the homogeneity of financial flows between a FI and its counterparties. Many have discussed ${ }^{[72,73]}$ why networks produced by the entropy method or as random graphs are not suited to characterize real world financial networks. Some important aspects of these discussions will be illustrated here and also in Section 4.

The following Figure 3 shows a random graph (left) with no specific structure or clustering and a highly tiered core-periphery graph (right) that characterizes OTC derivatives and to a lesser extent interbank credit markets. FIs in the periphery have no links between themselves while those in the core have dense interconnections amongst themselves ${ }^{[1,74]}$.

\section{Figure 3 Graphical representation: Random network (left), Tiered network with core- periphery structure (right)}

\footnotetext{
${ }^{17}$ A limited attempt at this was done in ${ }^{[67]}$ for an agent based model for CHAPS data based RTGS liquidity posting decision problem. Erev and Roth ${ }^{[68]}$ reinforcement learning capabilities were given to RTGS participants in the ACE model to see if they could learn to play socially efficient outcomes rather than individually rational ones that result in payment gridlocks.
} 


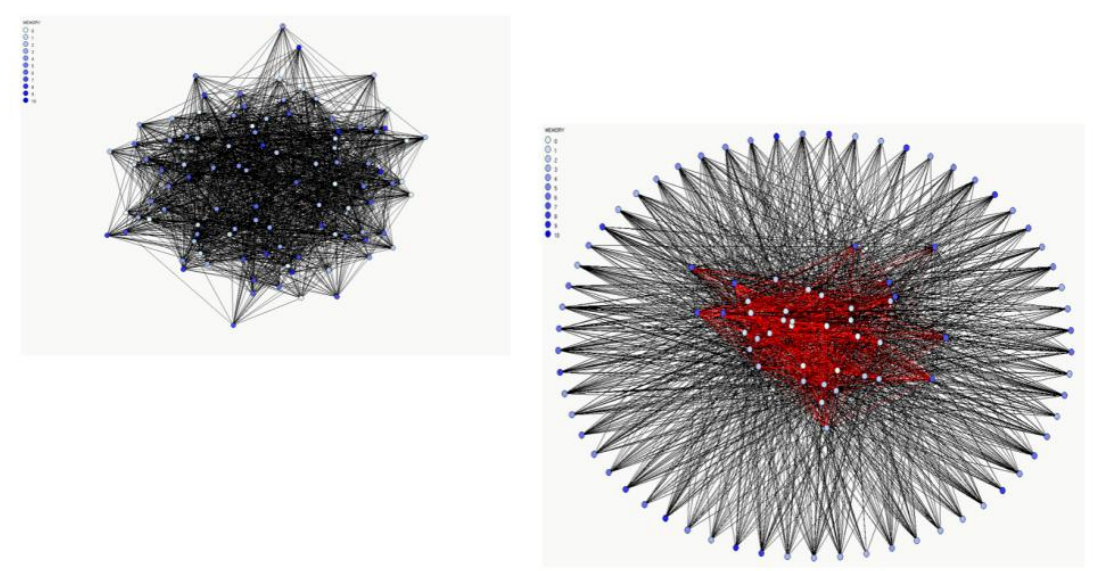

Markose et. al ${ }^{[7,40]}$ show how failure of a node, the one placed in the centre of Figure 4, propagates contagion in a random network structure (right) and that in a core-periphery sparse network (left). The latter depicts what it means to be too interconnected to fail, typical of the $\operatorname{CDS}{ }^{[32,40,41]}$ and other derivatives markets ${ }^{[1]}$. The highly tiered network has a central core of large banks which directly take a hit when a similarly connected bank collapses. The contagion stops at this point as the network loses connectivity with the demise of the superspreaders. But in the spirit of being too interconnected to fail, 4 top banks are brought down, Figure 4 (left). It is of course cold comfort that there are no second order failures spreading to the whole system when the first order shock wipes out the top 4 banks and some $70 \%$ of Tier 1 capital of the system. In contrast, the random network with no tiered structure and no bank is too interconnected, suffers as many as 17 (out of the 26) bank failures in a series of cascades which cannot be predicted, Figure 4 (right). Thus, in the context of controlling epidemics, the clustered network allows easier solutions in terms of inoculating the few super-spreaders, while in the random network the whole population has to be inoculated. Haldane ${ }^{[23]}$ calls such hub banks 'super-spreaders' and he recommends that super-spreaders should have larger buffers. The vulnerability of the tiered network to failures of any member of the core, as stated by Haldane ${ }^{[23]}$, requires that steps should be taken to reverse the current practice of more lenient reserves and collateral requirements for large broker dealers than their less connected counterparts. There is as yet no consensus as to how to operationalize the 'bail in' arrangements paid for by the FIs themselves for their systemic risk impact on others for being too interconnected.

Figure 4: Instability propagation in Clustered Empirical CDS Network (left) and in Equivalent Random Network (right) NB: Black nodes denote failed banks with successive concentric circles denoting the q-steps of the knock on effects. 


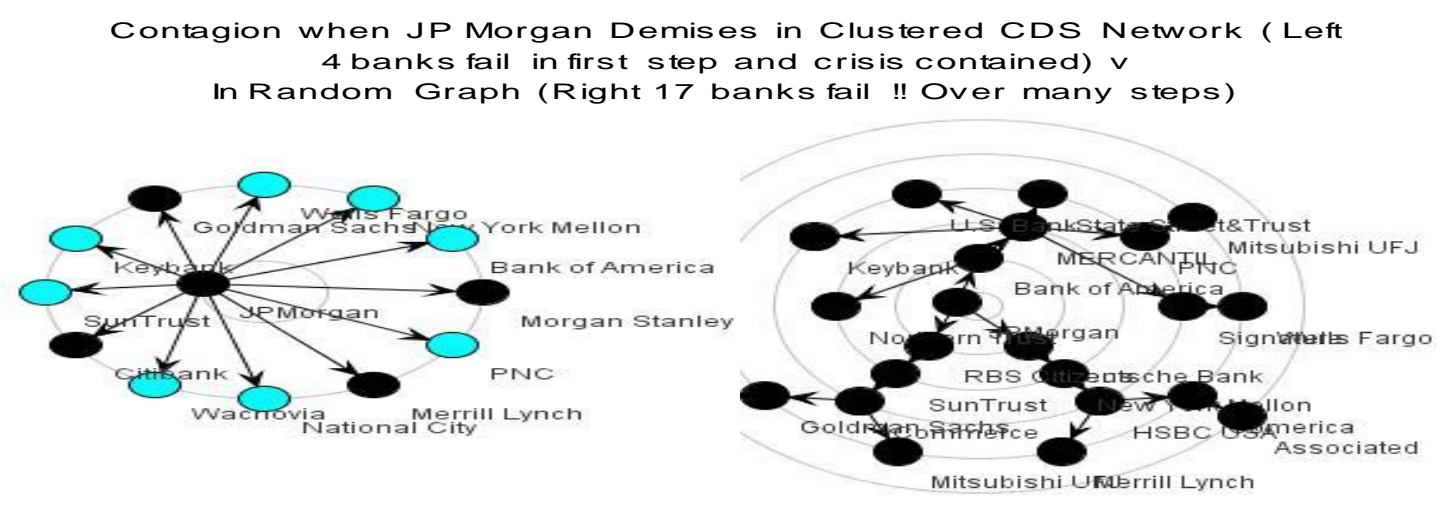

Source: Markose et al. ${ }^{[7]}$

\section{Systemic Risk Metrics: Statistical vs Causal linkages}

\subsection{Paradox of Volatility: Implications for Market Price based Systemic Risk Measures}

It is typical of most systemic risk measures, the bulk of these being based on market price data due to its availability, to first determine a measure for the overall system risk and then attribute each FI's marginal contribution to it. However, market price based systemic risk measures have been found not to work as early warning signals in that by the time they have 'spiked', the market will have tanked already. Figure 5.a shows the inherent inverse relationship and contemporaneous extreme co-movements in the FTSE-100 index and the (option price based) volatility index, VFTSE, which is publicly available. Those familiar with Hamilton ${ }^{[75]}$ regime switching models will know that the volatility of stock returns during market down turns are high while during boom or bull market conditions, it is low. The asymmetry in the correlation of stock returns is also well known with higher correlations recorded during market down trends than up trends ${ }^{[76]}$. Indeed, market data based volatility is at its lowest (Figure 5.a) just before the market crash and those who are ignorant of this can be lulled into a false state of complacency when systemic risk is building up on balance sheets through increased indebtedness ${ }^{[77]}$. In Figure $5 . b^{18}$, the Segoviano and Goodhart ${ }^{[71]}{ }^{19}$ credit default swap market price based banking stability index (green in Figure 5.b) spikes are at best contemporaneous with the crisis marked by the publicly available volatility indexes such as VIX or V-FTSE or at worse will show up after the crisis. This is the case of the distance to distress (DD) systemic risk measure used by Castren and Kovonius ${ }^{[50]}$ with a high DD signalling low distress. The DD measure "dropped sharply only after (italics added) the crisis had started" (ibid). They claim that the high DDs "in the years 2005-06 were mainly driven by historically low volatility ... even though from the market leverage Chart 6 , it is clear that vulnerabilities were gradually accumulating in the form of rising indebtedness in most sectors" (ibid).

\footnotetext{
${ }^{18}$ Figure 5.a was the one which I used in my talk at the 2010 IMF Workshop on Operationalizing Systemic Risk.

${ }^{19} \mathrm{I}$ 'm an avid fan of Goodhart's law, but have to part company here.
} 
Figure 5.a

"Paradox of stability" : Stock Index and Volatility Index

Paradox of Volatility (Borio and Drehman(2009); Minsky(1982))

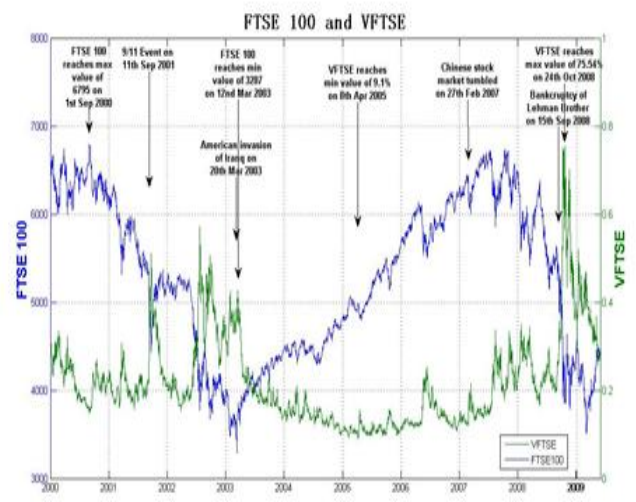

Figure 5.b

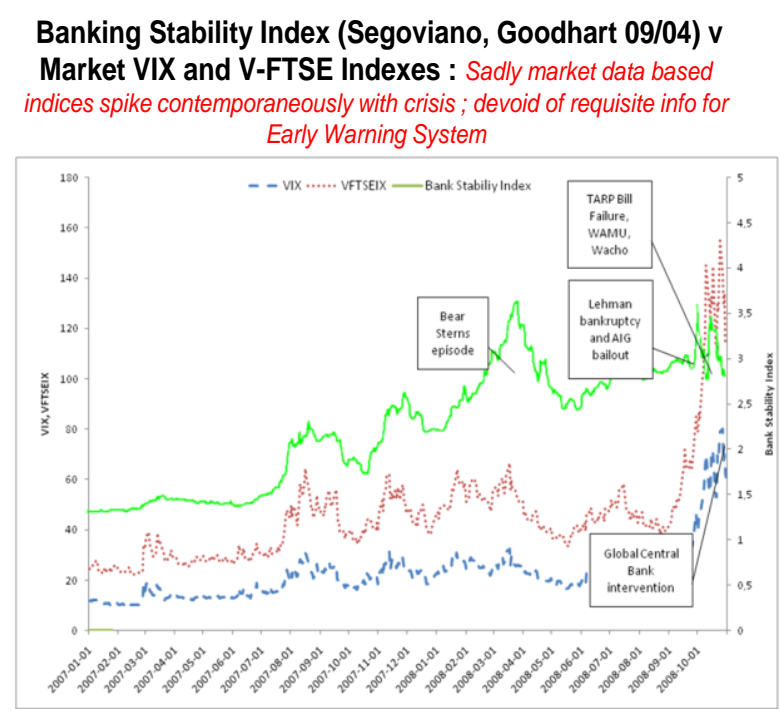

As the illusion of low market risk gets worse at exactly the moment before the crash, a Minsky ${ }^{[77]}$ type paradox of instability phenomena associated with procyclicality of leverage with asset price booms has recently been rediscovered by Borio and Drehmann ${ }^{\text {[29] }}$ in the form of the volatility paradox. This is like driving with a speedometer that has an iron clad logic which says that the faster one drives (viz. larger the bull market), the risk of having an accident falls (lower market risk or the volatility of the stock index returns).

Some of the market-based systemic risk measures that have been proposed are the following (see ${ }^{[33] ~[1]}$ for a discussion on these): Conditional VaR (CoVaR) ${ }^{[78]}$; Marginal System Expected Shortfall (MSES) ${ }^{[79]}$; Co-risk by Chau-Lan ${ }^{[80]}$; DIP (Distress Insurance Premium) by Huang et al. ${ }^{[81]}$; POD (Probability that at least one bank becomes distressed) by Segoviano and Goodhart ${ }^{[82]}$, Shapley-Value by Tarashev et. al. ${ }^{[83]}$ and Macro-prudential capital by Gauthier et. al ${ }^{[84]}$. Market price based systemic risk measures may mislead in the lead up to a crisis as they underprice risk during a boom. However, as correlations in market price data for the different FIs increase during market down turns, the cross sectional signals for the potential direction for contagion are strong and need close monitoring.

The market price data based systemic risk measures are popular because market prices are publicly available while bilateral data across counterparties and products have to be specially mandated. In view of the fact that the paradox of volatility in market price is particularly difficult to overcome, it is bound to become widespread practice to directly study balance sheet interconnections for systemic risk. To obtain their countercyclical forward Co-Var, Adrian and Brunnermeir ${ }^{[78]}$ have directly incorporated information on banks' balance sheet and financial liabilities/leverage ratios to overcome pro-cyclicality of market price data. Danielsson et.al. ${ }^{[85]}$ have shown that the popular market price based statistical systemic risk analysis such as Adrian-Brunnermeier Conditional VaR (CoVaR), and Marginal System Expected Shortfall (MSES) of Acharya et al. ${ }^{[79]}$, produce a very imprecise measure of an individual bank's absolute contribution to total systemic risk estimated and also the ranking 
of banks by the levels of systemic risk they create is not robust due to model error. Hence, though I'm of the view that during market down turns it is important to monitor the cross section information on the direction of contagion based on correlation in market price data for the FIs, for a lack of transparency in model generated data and systemic risk analytics (see, footnote 9) it is unlikely that a market price based measure of individual FI contributions to systemic risk can be imposed as a Pigou tax to engineer 'bail in' arrangements paid for by FIs.

\subsection{Systemic Risk Modelling With Bilateral Balance Sheet Data-based Network Models}

Bilateral balance sheet based network models are structural models that aim at depicting causal chains between FIs rather than rely solely on statistical correlations to estimate interconnections which still remain the basis of most extant financial contagion models. Though most systemic risk approaches, first, determine a measure for the overall system risk and then attribute each FI's marginal contribution to it, interestingly, the bilateral balance sheet based financial network model of Cont et. al. ${ }^{[73]}$ gives only measures that rank the systemic risk contributions of the different FIs and that of Martinez et. al. (2012) gives different network centrality statistics for the FIs. They do not give a metric for the instability of the network structure as a whole. The Cont et. al. ${ }^{[73]}$ contagion index and ranking of a FI is based on the expected loss of capital for the system as a whole generated from stress tests that follow with the failure of a FI. The factors explaining these contagion indexes are then obtained by quantile regressions. Martinez et. al ${ }^{[86]}$ give an exhaustive listing of network centrality parameters but they are not related to whether the financial network as a whole has become more or less stable.

Bluhm and Krehnan ${ }^{[87]}$, in part, aim to to extend the Shapley value allocation of systemic importance of a FI first specified by Tarashev et. al. ${ }^{[33]}$ in a non-network setting of bilateral financial obligations. Bluhm and Krehnan ${ }^{[87]}$ propose a system value-at-risk at a high confidence level of total losses to FIs' assets from multivariate shocks. In a network setting, instead of taking the marginal contribution of a FI to system-value-at-risk calculated in the case of every possible coalition of FIs, the Myerson-Shapley value (see ${ }^{[88]}$ )|requires that the marginal contribution is calculated in terms of the weighted sum of all possible network structures of one FI with all other FIs. Further, not withstanding the NP-hard problem here, with N number of FIs, the Myerson-Shapley value for a FI's contribution to systemic risk requires the FI's marginal contribution to all possible $2^{\mathrm{N}-1}$ topological network configurations which includes a given FI are weighted equivalently on grounds of fairness ${ }^{[89]} \cdot{ }^{20}$ As discussed

${ }^{20}$ That is, the weight, $\mathrm{p}_{\mathrm{i}, \mathrm{s}}$ is the same for all networks with the same number of nodes and is given by
$\mathrm{p}_{\mathrm{i}, \mathrm{s}}=\frac{(|S|-1) !(|N|-|S|) !}{|N| !}$, if $\mathrm{i} \in \mathrm{S}$. Here, $|\mathrm{S}|$ denotes the cardinality of a set $\mathrm{S}$ where $\mathrm{S}$ is a subset of set of all nodes, N, and S includes the ith FI. The Myerson-Shapley value (MSV) is given by the formula: $\phi_{i}^{M S V}(\mathrm{v}(\mathrm{c}(\mathrm{g}(\mathrm{S}))=$ $\sum_{S \subseteq N: i \in S} p_{i, S}[v(c(g(S))-v(c(g(S \backslash i))]$. Here, $v$ is the value function, such as the system value-at- risk, of a connected subgraph, in our case here of financial liabilities between FIs, denoted by $\mathrm{c}(\mathrm{g}(\mathrm{S}))$ and $\mathrm{v}(\mathrm{c}(\mathrm{g}(\mathrm{S} \backslash \mathrm{i}))$ is the same value function calculation done for the connected sub-network without i. This is explained in Section 3.1 of Kirman et.al (2007). 
in Section 2, given the characteristic topology of financial networks is far from random, it is not clear to me how all the same sized subnetworks that contain a FI, can be weighted alike irrespective of topology. It is often the case that some simplifying assumptions have to be made to overcome the dimensionality problem in the Myerson-Shapely value calculations. Bluhn and Krehnan ${ }^{[87]}$ consider only the maximum size coalition or network (ibid, see Appendix A) and Bluhm et. al. ${ }^{[21]}$ assume a random sampling of $\mathrm{k}$ different permutations.

Instability of large networks was first studied by May ${ }^{[33,34]}$. In these papers, May showed that network stability depends on the size of the maximum eigenvalue of an appropriate dynamical characterization of the network system. For a sparse network which has a matrix of bilateral entries given by (standard) normally distributed real numbers, May ${ }^{[33,34]}$ derives a closed form solution for the maximum eigenvalue of the network. The May stability condition is defined in terms of 3 network parameters: $\mathrm{N}$, the number of nodes, $\mathrm{C}$, the probability that any two randomly selected nodes are connected, and $\sigma$, the standard deviation of node strength. ${ }^{21}$ When the latter statistic is large, it indicates the asymmetry in the number and weights of the out links that some nodes have relative to others. A network is determined to be unstable if its maximum eigenvalue is greater than 1 , viz. $\sqrt{N C} \sigma>1$. May showed that an increase in the number of nodes in a network along with its connectivity that is also accompanied by a growing standard deviation in node strength, contributes to instability. This implies the following trade off, not sufficiently understood by economists in their studies of financial networks: if the size and connectivity of a network grows, unless it is becomes more homogenous in node strength, it will become more unstable. Conversely, large networks such as those for financial derivatives, Markose ${ }^{[1]}$, which have fat tailed link distribution and a large standard deviation in node strength, need to have very low connectivity to remain stable. Thus, network construction algorithms such as the entropy maximization one ${ }^{[72]}$ by homogenizing cell entries can reduce network instability.

Markose ${ }^{[1]}$, uses the insights from May ${ }^{[33,34]}$ and Wang et. al. ${ }^{[90]}$ to give an appropriate dynamical characterization of the financial network system and determine the stability conditions in terms of a threshold rate of the policy variable, viz. Tier 1 Capital. This has led to the so called eigen-pair method in Markose ${ }^{[1]}$ in which there is a simultaneous determination of the maximum eigen-value of the networked system of bilateral liabilities of FIs adjusted for Tier 1 capital and the corresponding right eigen-vector centrality measure for who contributes to instability.

\subsection{Markose $^{[1]}$ Eigen- Pair Method For Systemic Risk Analytics}

In order to simultaneously determine the stability of the financial network system and the contribution of each FI to this, it is useful to model the dynamics of failures as in the epidemiology literature, viz. as the spread of 'disease' from other failed FIs. In the classic

\footnotetext{
${ }^{21}$ Node strength here is a simple measure given by the row sum of the matrix.
} 
Furfine $^{[30]}$ contagion stress test, any arbitrarily selected trigger bank is monitored for the direct and indirect failures it brings about on counterparties via their exposures to the trigger bank, relative to their own capital.

The causal direction of the contagion and hence systemic risk of a FI, follows from the 'trigger' FI, i, owing its counterparty $\mathrm{j}$ more than what $\mathrm{j}$ owes i, relative to $\mathrm{j}$ 's Tier 1 capital. This is denoted by the positive entries net liabilities to $i$ to $j$ relative to $j$ 's capital given by elements $\theta_{\mathrm{ij}}=\left(\mathrm{x}_{\mathrm{ij}}-\mathrm{x}_{\mathrm{ji}}\right)^{+} / \mathrm{C}_{\mathrm{j} 0}$ in matrix (1) for those pairs of FIs which have a direct financial links. ${ }^{22}$ Here, $C_{j 0}$ is $\mathrm{j}$ 's initial capital. Hence, the matrix $\Theta$ that is crucial for the contagion analysis will have elements given as follows:

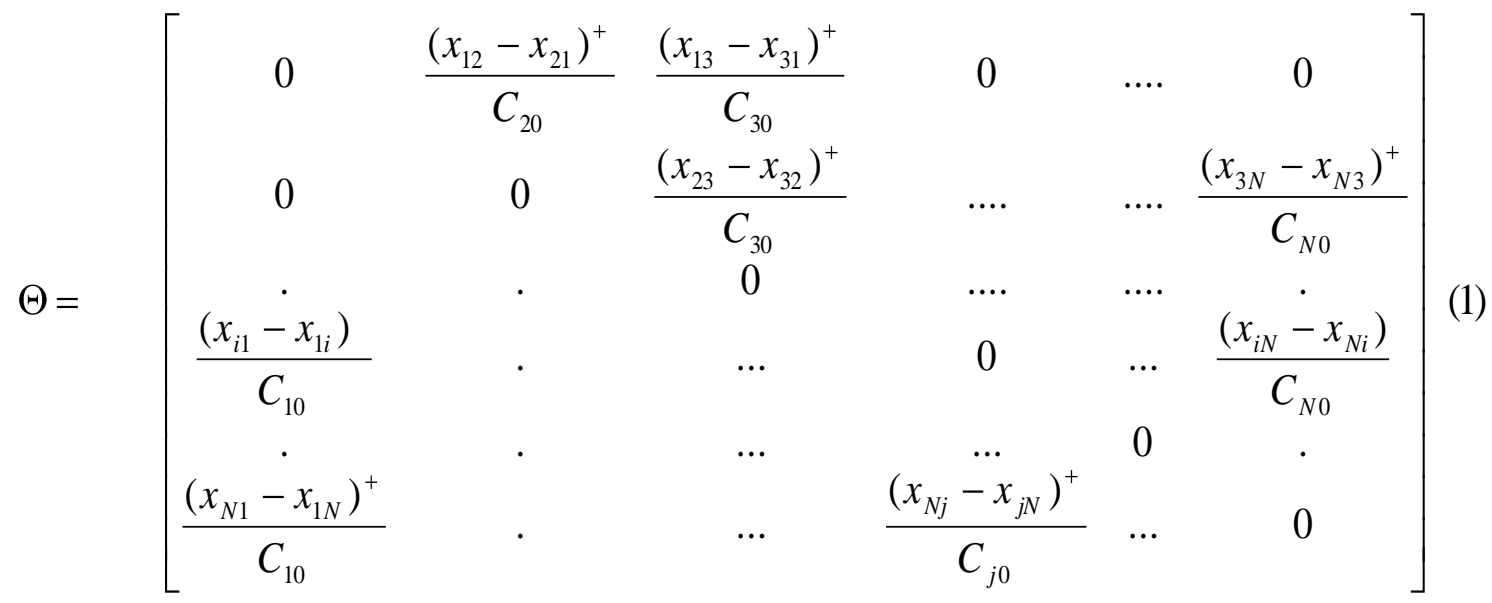

Failure of a FI is usually determined by the criteria that losses exceed a predetermined buffer ratio, $\rho$, of Tier 1 capital. In the epidemiology literature ${ }^{[90]}, \rho$ is the common cure rate and $(1-\rho)$ is the rate of not surviving in the worst case scenario. The dynamics relating to the probability of failure of each ith FI at a given time step $q+1$ denoted by $u_{i q+1}$, given $j$ counterparties of $i$ have failed at the previous time step q. As shown in the Appendix, this is determined by (i) i's own survival probability given by the capital $\mathrm{C}_{\mathrm{iq}}$ it has remaining relative to initial capital $\mathrm{C}_{\mathrm{i} 0}$ (ii) and the sum of 'infection rates' defined by the sum of net liabilities of its $\mathrm{j}$ failed counterparties relative to its own capital is given by the term $\sum_{j} \frac{\left(x_{j i}-x_{i j}\right)^{+}}{c_{i 0}}$. Note the 'infection rate' or how counterparties impact on an FI is pair wise heterogeneous.

It can be shown in Markose ${ }^{[1]}$ and as outlined in the Appendix, the stability of the network system involving matrix $\Theta$ in (1) requires that its maximum eigenvalue is less than the homogeneous Tier 1 capital threshold, $\rho$ :

$$
\lambda_{\max }\left(\Theta^{\prime}\right)<\rho .
$$

\footnotetext{
${ }^{22}$ In principle, this should be adjusted for master agreements that permit bilateral netting and also for collateral.
} 
If this condition is violated, a negative shock, in the absence of outside interventions, can propagate through the networked system as a whole and cause system failure.

In the management of contagion and the design of the super-spreader tax or inoculation measures, it is important to understand the relationship between the maximum eigenvalue of the $\Theta$ matrix and its corresponding, respectively, right and left eigenvectors $\widetilde{\boldsymbol{v}_{\mathbf{1}}}$ and $\boldsymbol{v}_{\mathbf{1}}$. Note,

a matrix (with non-negative values) and its transpose have the same maximum eigenvalue. However, right and left eigenvectors corresponding to the $\lambda_{\max }$, are different. Here, the right eigenvector denoted by $\widetilde{v_{1}}$ corresponds to the systemic risk metric for FIs, relating to the

damage a FI can inflict on others as the direction of impact in elements $\theta_{\mathrm{ij}}$ in matrix (1) arise from the liabilities of $i$ to $j$. In contrast, the left eigenvector denoted by $\mathbf{v}_{\mathbf{1}}$ relates to the exposure index of FIs, viz. the damage a FI faces from others from elements $\theta_{\mathrm{ji}}$ of the matrix transpose $\Theta^{\prime}$ of (1). The power iteration algorithm that determines the maximum eigenvalue of the matrix $\boldsymbol{\Theta}$, also determines its corresponding eigen-vector, $\widetilde{v_{1}}$, which yields the rank

order of the centrality of the FIs vis-à-vis the instability metric of the system given by $\lambda_{\max }$. What is important to note, as discussed in Markose (2012), is how the power iteration algorithm yields a simple relationship between the upper bound of $\lambda_{\max }$ and the maximum row (column) sum ${ }^{23}$ of the matrix $\boldsymbol{\Theta}^{\prime}(\boldsymbol{\Theta}$ in (1)). Further, high eigen-vector central, EVC, nodes score highly because their connections to high-scoring nodes contribute more to the EVC score of the node in question than equal connections to low-scoring nodes. Denoting $\tilde{v}_{i}$

as the right eigenvector centrality for the $i^{t h}$ node for matrix $\Theta$, the centrality score is proportional to the sum of the centrality scores of all nodes to which it is connected. Hence,

$$
\tilde{v}_{i}=\frac{1}{\lambda_{\max }} \sum_{j} \theta_{i j} \tilde{v}_{j}
$$

Using vector notation, the eigenvalue equation for the matrix in (1) for the eigen-pair $\left(\lambda_{\max }\right.$, $\widetilde{v_{1}}$ ) is given as:

$$
\Theta \widetilde{v_{1}}=\lambda_{\max } \widetilde{v_{1}}
$$

Thus, high EVC FIs with high connectivity to a large number of highly connected counterparties can contribute greatly to the instability of the system when $\lambda_{\max }>\rho$. Note, using the eigenvalue equation, the left eigenvector is defined as

$$
\mathbf{v}_{\mathbf{1}} \Theta=\Theta^{\prime} \mathbf{v}_{\mathbf{1}}=\lambda_{\max } \mathbf{v}_{\mathbf{1}} .
$$

\footnotetext{
${ }^{23}$ Denoting the row sum of the ith row of $\Theta^{\prime}$ by $S_{\mathrm{i}}=\sum_{j} \theta_{j i}, \lambda_{\max } \leq \max S_{i}$.
} 
In $\Theta^{\prime} \mathbf{v}_{\mathbf{1}}$ as the matrix transpose of (1) is involved with elements $\theta_{\mathrm{ji}}$ denoting exposure of $\mathrm{i}$ to $\mathrm{j}$ (rather than the case of the impact of $i$ 's liabilities on $j$ in $\theta_{i j}$ in (4)), the rank order of the left eigen-vector $\mathbf{v}_{\mathbf{1}}$ gives the measure of those that are most vulnerable or exposed to others in the system.

In what follows, the role of row sums in the stability of the system $\Theta^{\prime}$ will be exploited to determine the Pigou tax for a FI as a function of its eigen-vector centrality, denoted by $\tau\left(\tilde{v}_{i}\right)$. Given the relative simplicity in the determination of the above systemic risk metrics for the matrix in (1) which yields the appropriate dynamical system for the demise of FIs from failing counterparties, the eigen-pair method was used on the bilateral financial data for a large Asian interbank market for quarters from mid 2010 to end of 2011. Remarkably, a situation reminiscent of the aggressive borrowing on the interbank, short term money markets done by UK banks that demised in the 2007 crisis was observed. From mid-2011, a bank that was ranked number 5 or 6 in terms of eigenvector centrality in mid 2010 was seen to have catapulted to the most eigen-vector central bank within a few quarters. A combination of increased connectivity of the FI and its large liabilities relative to the distribution of capital in the system accounts for its dominant eigen-vector central position. Clearly, what is rational/profitable for this bank that enabled it to increase its loan market share led to an adverse loss of stability for the interbank system as a whole. System wide capital losses from a Furfine ${ }^{[30]}$ type stress test, with this bank as the trigger, jumped to $29.4 \%$ from more modest levels of $6 \%-14 \%$ in previous quarters when other banks were dominant in terms of eigen-vector centrality. This real world exercise shows that it is not sensible to have a priori lists for SIFIs in macro-prudential policy and that sudden jumps in eigen-vector centrality of a bank should give cause for concern.

\subsection{A Progressive Pigou tax for Eigen-vector Central FIs}

Each FI is taxed according to its right EVC $\tau\left(\tilde{v}_{i}\right)$ in order for the FI to internalize the costs that they inflict on others by their failure and to mitigate their contribution to network instability as given by $\lambda_{\max }$. The progressive nature of the tax justifies the moniker 'superspreader' tax. The rationale behind the application of the right eigenvector centrality of a node as the basis of the Pigou tax is to enable a FI to provide a buffer proportional to its own capacity to propagate contagion.

The network stabilization algorithm has been called the EIG algorithm, Markose ${ }^{[1]}$, in keeping with Giakkoupis et. al ${ }^{[91]}$. The main objective of the EIG algorithm is to apply to each i a tax denoted by $\tau\left(\tilde{v}_{i}\right)$ in order to bring down the maximum eigenvalue of the $\boldsymbol{\Theta}$ matrix to the desired threshold $\rho$. The details of this can be found in Markose ${ }^{[1]}$ and Markose et. al ${ }^{[40]}$.

The nature of the systemic risk stabilization super-spreader fund is that it operates like an escrow fund. The funds commensurate to each FI's surcharge as a proportion of its Tier 1 capital are collected at some initial point whether within a centralized clearing platform (CCP) context or by the regulatory authority. The funds are deployed at the time of potential failure of a FI for the collective good to mitigate tax payer bailouts of the failing bank in 
order to prevent a financial contagion. Some backtesting of this has been done in Markose ${ }^{[1]}$ and Markose et. al ${ }^{[40]}$. Further, the right EVC of a FI as a metric for its systemic importance has been empirically validated as a good proxy of the actual losses of capital that it can bring about as a trigger in a Furfine contagion stress test for the Indian financial system. The correlation in the rank order of the EVC of FIs and that for the capital losses they bring about as a trigger in the Furfine stress test was over $98 \%$ in all the 4 quarters for which it was analysed.

Many of the financial network models for systemic risk modelling ${ }^{[92,73]}$ use the network framework to study the impact of one or more of the factors that are known to accompany and exacerbate a financial crisis. These factors are strictly extraneous to the weighted network of financial flows that represent contractual obligations. These factors include : (i) The impact of common macro-economic shocks such as a rise in interest rates or a fall in house prices that depress balance sheets, (ii) Second order effects from fire sales and deleveraging ${ }^{[21]}$. (iii) Probabilistic considerations of future losses arising from the course of a contagion. These are interesting stress tests that can inform regulators of the extent of losses under different scenarios. However, going by the spirit of financial market laws, a FI cannot be held culpable for damage to others from pre-existing macro-economic conditions such as loose monetary conditions or future market conditions that may arise, for example, during deleveraging that are unknowable at the time of contracting. The eigen-pair method has the advantage that it is based only on extant bilateral contractual financial obligations of FIs and their Tier 1 capital and the network topology that is implied by the certified bilateral data submissions.

\section{Concluding Remarks}

As noted by Winter [93] "monitoring and understanding the overall health of institutions and markets and the connections between them across the entire breadth of the financial system" is an ambitious objective for which central banks and financial authorities have been given enormous powers as with the Dodd-Frank Act in the US and the 2012 Financial Services Act in the UK. One of these powers is that of mandating requisite financial data from FIs to overcome problems of market failure. In addition, the 2007 crisis has shown that extant policy models and quantitative tools are too antiquated for the tasks of macro-prudential policy which requires holistic visualization of 'big' financial data. The ICT oriented MAFN framework has been proposed as a way of tackling this. With these new ICT tools, the mapping of actual financial interconnections to analyse propagation of instability or contagion in the system can be done at a level of granularity and virtual depiction of reality not available in mainstream macro-economics tool box. Also as we must avoid "official definitions of systemic risk that have left out the role of government officials in generating it", Kane ${ }^{[69]}$, MAFN simulation platforms are well suited to conduct "wind tunnel" tests of policy both prior to implementation and to monitor it on an on-going basis for its capacity to generate race to the bottom type tactics or destabilizing carry trades.

There are fundamental problems with regard to market price based systemic risk measures to do with the volatility paradox and a lack of empirical robustness with calibrations in the 
construction of financial interconnections from balance sheet and off balance sheet data which is aggregated over all counterparties. I have, therefore, emphasized the need for central banks to mandate the required bilateral data from bank and non-bank FIs with sufficient granularity in terms of funded and unfunded balance sheet items. This has been done since mid 2010 at the Reserve Bank of India with the some promising results for systemic risk monitoring.

A lot of focus has been given to 'bail in' arrangements as part of the resolution process at the time of failure of a FI to mitigate tax payer bailouts. However, one of the important lessons of the 2007 crisis is that prevention is a good policy. The 'bail in' funds paid for by FIs themselves in the form of a Pigou tax has been proposed for the FIs to internalize the externalities from being 'too interconnected' relative to available capital. The eigen-pair method proposed has the advantage of being transparent, simple to calculate and progressive. Which FI is the most eigen-vector central can change over time and this can be monitored over time. The Markose ${ }^{[1]}$ eigen-pair method eschews many features, present in other proposals for systemic risk measures, that are extraneous to the actual matrix of contractual obligations between FIs. While these features are important in the context of macroprudential stress testing, I have argued that they cannot reasonably be made the basis of a systemic risk Pigou tax to be paid for by a FI. Preliminary back testing of the 'bail-in' escrow fund garnered from the eigen-vector centrality based Pigou taxes can nip in the bud potential contagion effects from the failure of a large SIFI within the context of the network of obligations for which it is designed.

\section{Appendix}

The dynamics characterizing transmission of 'infection' in a financial networked system can be given by

$$
u_{i q+1}=(1-\rho) u_{i q}+\sum_{j} \frac{\left(x_{j i}-x_{i j}\right)^{+}}{c_{i \mathrm{i}}} u_{j q}^{1}
$$

Here, we have a FI's own metric of failure at $q$ which is given by $u_{i q}=\left(1-C_{i q} / C_{i 0}\right)$, where $\mathrm{C}_{\mathrm{iq}} / \mathrm{C}_{\mathrm{i} 0}$ is the ratio of capital at $\mathrm{q}$ and capital at initial date. The second term in (A.1) involves the losses from counterparties, $\mathrm{j}$, that fail at $\mathrm{q}$ and these are denoted by the an indicator function which is set equal to 1 . The sum of 'infection rates' is defined by the sum of net liabilities of its $\mathrm{j}$ failed counterparties relative to its own capital is given by the term $\sum_{j} \frac{\left(x_{j i}-x_{i j}\right)^{+}}{c_{i 0}}$.

In order for the eigen-pair stability analysis to be used, in matrix notation the dynamics of financial contagion takes the following form: ${ }^{24}$

\footnotetext{
${ }^{24}$ In general, the unconstrained case of (A.1) is used, $u_{i q+1}=(1-\rho) u_{i q}+\sum_{j} \frac{\left(x_{j i}-x_{i j}\right)^{+}}{c_{i \mathrm{io}}} u_{\mathrm{jq}}$. That is, the indicator function that signifies only banks that fail at $q$ no longer applies and we have a weighted sum of the impact of all $j$ counterparty banks, $j \neq i$ in the second term.
} 


$$
\boldsymbol{U}_{q+1}=\left[(1-\rho) \mathbf{I}+\Theta^{\prime}\right] \boldsymbol{U}_{q}=\boldsymbol{Q} \boldsymbol{U}_{q}
$$

Here, $\boldsymbol{\Theta}^{\prime}$ is the transpose of the matrix in (1) with each element $\theta_{i j}{ }^{\prime}=\theta_{j i}$ and $\boldsymbol{I}$ is the identity matrix.

The system stability of (A2) will be evaluated on the basis of the power iteration of the matrix $\mathbf{Q}$. From (A2), $\boldsymbol{U}_{q}$ takes the form:

$$
\mathbf{U}_{\mathrm{q}}=\mathbf{Q}^{\mathrm{q}} \mathbf{U}_{\mathbf{0}}
$$

Markose (2012) shows how the stability of the system in (A.3) as q tends to infinity, requires that the maximum eigen-value, $\lambda_{\max }$, is less than the common threshold on capital, $\rho$.

\section{References}

1. Markose, S. (2012) Systemic risk from global financial derivatives: A network analysis of contagion and its mitigation with super-spreader tax. International Monetary Fund Working Paper. November; 12(282). Available from: http://www.imf.org/external/pubs/ft/wp/2012/wp12282.pdf

2. Buiter, W. The unfortunate uselessness of most 'state of the art' academic monetary economics. 2009, Available from: http://www.voxeu.org/index.php?q=node/3210

3. Stiglitz, JE. (2011) Rethinking Macroeconomics: what failed, and how to repair it. Journal of European Economic Association. 9(4): 591-645.

4. Blundell-Wignall, A. and Atkinson P. (2008) The subprime crisis: causal distortions and regulatory reform. In: Bloxham $\mathrm{P}$, Kent $\mathrm{C}$, editors. Lessons from the financial turmoil of 2007 and 2008. Proceedings of a conference held at the H.C. Coombs Centre for Financial Studies, Kirribilli; Jul 14-15; Sidney, Australia: Reserve Bank of Australia.

5. Brunnermeier, M., Crockett, A., Goodhart, C., Persaud, A., Shin, H. (2009) The fundamental principles of financial regulation. Geneva Reports on the World Economy 11, International Center for Money and Banking Studies.

6. Hellwig, M. (2010) Capital regulation after the crisis: business as usual?. CESifo DICE Report, Journal for Institutional Comparisons. 8(2).

7. Markose, S., Giansante, S., Gatkowski, M. and Shaghagi, A.R. (2010) Too interconnected to fail: financial contagion and systemic risk in network model of CDS and other credit enhancement obligations of US banks. University of Essex Economics Department Discussion Paper Series. 2010 Feb; 683.

8. Wieland,V. (2010) Model Comparison and Robustness: A Proposal for Policy Analysis after the Financial Crisis, Mimeo, Goethe University Frankfurt, CEPR and CFS. 
9. Colander, D., Howitt, P., Kirman, A., Leijonhufvud, A., Meherling, P. (2008) "Beyond DSGE models: toward an empirically based Macroeconomics. Papers and Proceedings of the American Economic Association, American Economic Review. 98: 236-240.

10. Gorton, G., Metrick A.(2012) Securitized banking and the run on Repo. Journal of Financial Economics. 104 (3): 425-51.

11. Schularick M., Taylor, A. (2012) Credit booms gone bust: monetary policy, leverage cycles, and financial crises, 1870-2008. American Economic Review. 102 (2).

12. Markose, S., Loke, Y.J. Network Effects of Cash-Card Substitution In Transactions and Low Interest Rate Regimes. Economic Journal. 2003; 113: 456-476.

13. Marimon R, Nicolini JP, Teles P. Electronic money: the end of inflation?. Institute for Empirical Macroeconomics, Federal Reserve Bank of Minneapolis. 1997; Discussion Paper 122.

14. Markose, S. (2005) Computability and evolutionary complexity: markets as complex adaptive systems (CAS). Economic Journal. 115: F159-F192.

15. Kirman, A. (1992) Whom or what does the representative individual represent?. Journal of Economic Perspectives. 6: 117-136.

16. Kirman A.(1997)The economy as an evolving network. Journal of Evolutionary Economics. 7(4): 339-353.

17. Caruana, J. (2010) Macroprudential policy: working towards a new consensus. Speech at The emerging framework for financial regulation and monetary policy. April 23; Washington D.C., USA.

18. Clement, P. (2010) The term "macroprudential": origins and evolution. BIS Quarterly Review. March.

19. Alessandri P. and Haldane, A. (2009) Banking on the state. Paper based on presentation at the Federal Reserve Bank of Chicago, 12 International Banking Conference.

20. Acharya, V., Pedersen, L., Philippon T., Richardson M. (2009) Regulating systemic risk. In V. Acharya and M. Richardson (eds.), Restoring financial stability: how to repair a failed system. New York: Wiley; 2009.

21. Bluhm, M., Faia, E., Krahnen J.P. (2013) Endogenous banks' networks, cascades and systemic risk. Goethe University, Mimeo.

22. Pigou AC. (1946) The economics of welfare. 8th Ed. London: Macmillan.

23. Haldane, A. (2009) Rethinking the financial network. Speech delivered at the Financial Student Association, Amsterdam. 
24. Flood, M., Mendelowitz, A., Nichols, B.(2012) Monitoring financial stability in a complex world. In Lemieux V, editor. Financial analysis and risk management: data governance, analytics, and life cycle management. Springer Verlag.

25. Bisias, D., Flood, M., Lo, A., Valavanis, S. (2012) A survey of systemic risk analytics. Office of Financial Research. WP No. 0001.

26. Huertas, T.F. (2011) The Road to Better Resolution: From Bail out to Bail in. Available from http://www2.lse.ac.uk/fmg/events/conferences/2011/DBWorkshop_14Mar2011/4ThomasHuertas.pdf.

27. Dewatripont, M., Freixas X. (2010) Bank resolution. Financial Markets Group, 'Bail-in' and Special Resolution Workshop, London School of Economics.

28. Moosa, I. (2010) The myth of too big to fail. Journal of Banking Regulation. 11(4): 319-333.

29. Borio, C. and Drehmann M.(2009) Towards an operational framework for financial stability: 'Fuzzy' measurement and its consequences. In Banco Central de Chile, editor. Financial stability, monetary policy and central banking. Also available as BIS WP No 284.

30. Furfine, C.H (2003) Interbank exposures: quantifying the risk of contagion. Journal of Money, Credit and Banking. 2003; 35(1): 111-28.

31. Upper, C. (2011) Simulation methods to assess the danger of contagion in interbank markets. Journal of Financial Stability, Elsevier. 7(3):111-125.

32. Yellen, J.(2013) Interconnectedness and systemic risk: lessons from the financial crisis and policy implications. Board of Governors of the Federal Reserve System at the American Economic Association/American Finance Association Joint Luncheon; 2013 Jan 4; San Diego, California.

33. May, RM.(1972) Will a large complex system be stable?. Nature : 238: 413-414.

34. May, RM. (1974) Stability and complexity in model ecosystems. Princeton University Press.

35. Bisias, D., Flood, M., Lo, A., Valavanis, S. (2012) A survey of systemic risk analytics. Office of Financial Research. WP No. 0001.

36. Thornton, H. (1938)An enquiry into the nature and effects of the paper credit of Great Britain; 1802. Introduction by Hayek F. (1938).

37. Singh, M., Aitken J. (2010) The (Sizable) role of rehypothecation in the shadow banking system. IMF: WP 10/172.

38. Singh, M.(2011) Velocity of pledged collateral- analysis and implications. IMF WP 11/256.

39. Milne, A. (2013) Register, cap and trade: a proposal for containing systemic liquidity risk. Economics: The Open-Access, Open-Assessment E-Journal. Available from: http://dx.doi.org/10.5018/economics-ejournal.ja.2013-7. 
40. Markose S., Giansante S., Shaghaghi A. (2012) Too interconnected to fail financial network of U.S. CDS market: topological fragility and systemic risk. Journal of Economic Behavior and Organization. 2012 August; 83(3):627-646. Available from: http://www.sciencedirect.com/science/article/pii/S0167268112001254

41. Markose S., Oluwasegun, B., Giansante, S. (2012) Multi-Agent Financial Network (MAFN) model of US Collateralized Debt Obligations (CDO): regulatory capital arbitrage, negative CDS carry trade and systemic risk analysis. In: Alexandrova-Kabadjova B, MartinezJaramillo S, Garcia-Almanza AL, Tsang E.(Eds). Simulation in Computational Finance and Economics: Tools and Emerging Applications. IGI Global, August 2012. Also available from University of Essex Economics Discussion Papers 714.

42. Darby M. (1994) Over the counter derivatives and systemic risk to the global financial system. NBER. WP No. 4801.

43. Verstein A. (2011)The misregulation of person-to-person lending. UC Davis Law Review. 2011; 45: 445- 529.

44. Hayek F.A. (1976) Denationalization of money. Also available in Institute of Economic Affairs.

45. White, W. (2006) Is price stability enough ? Bank of International Settlements. WP No. 205.

46. Borio C., White W. (2004) Whither monetary and financial stability? The implications of evolving policy regimes. BIS. WP No.147.

47. Pozsar, Z., Adrian, T., Ashcraft, A., Boesky, H. (2012) Shadow Banking. Federal Reserve Bank of New York Staff Report No. 458.

48. Skaperdas S. (2011) Policy making in the Eurozone and the Core vs. Periphery Problem. CESifo Forum, Ifo Institute for Economic Research at the University of Munich. 12(2): 1218.

49. Bean, C., Paustian M., Penalver, A., Taylor, T. (2010) Monetary policy after the fall. Federal Reserve Bank of Kansas City Annual Conference; Jackson Hole, Wyoming.

50. Castren, O., Kavonius I.K. (2009) Balance sheet interlinkages and macro-financial risk analysis in the Euro area. ECB. WP No. 1124.

51. Barwell R, Burrows O.(2011) Growing fragilities? Balance sheets in the great moderation. Financial Stability. Bank of England Discussion Paper No. 10.

52. Buchanan M. (2009) Meltdown modelling: could agent-based computer models prevent another financial crisis? Nature. Aug $6: 460: 680-682$. Available from: http://www2.econ.iastate.edu/tesfatsi/MeltDownModeling.Nature080609.Buchanan.pdf

53. Farmer, D., Foley, D. (2009) The economy needs agent based modelling. Nature. 460: 685686. 
54. Markose,S. (2011) "Multi-Agent Financial Modelling and Complexity Approach to Systemic Risk Monitoring for G10 and BRICs: A Post 2007 Perspective" Talk given at Reserve Bank of India, Financial Stability Unit, August 2010.

55. Haldane,A. (2013) Speech at BCBS Workshop On Regulatory Data and Systemic Risk Analytics, Bank of England.

56. Tesfatsion L., Judd K.L. (2006) editors. Handbook of Computational Economics, Volume2: agent-based Computational Economics. Handbooks in Economics Series. North-Holland, Amsterdam; 2006.

57. LeBaron B.(2000) Agent based Computational Finance: Suggested Readings and Early Research. Journal of Economic Dynamics and Control.24: 679-702.

58. Schelling T. (1971) Dynamic models of segregation. Journal of Mathematical Sociology. 143-186.

59. Arthur, W.B., Holland J., LeBaron B., Palmer R, Taylor P. (1997) Asset pricing under endogenous expectations in an artificial stock market. In: Arthur W.B, Durlauf S, Lane D, editors. The Economy as an Evolving Complex System II. Addison Wesley: Reading MA. 1997: 15-44.

60. Thurner S., Farmer J.D, Geanakoplos J.(2012) Leverage causes fat tails and clustered volatility. Quantitative Finance. 12(5): 695-707.

61. Johnson, J. (2011) Hypernetworks in the science of complex systems. Imperial College Press.

62. Johnson, J.(2006) Hypernetworks for reconstructing the dynamics of multi-level systems. European conference on complex systems. Oxford University.

63. Balakrishnan, S., Chu V., Hernandez, M., Ho, H., Krishnamuthy R., Liu, S., Pieper J., Pierce J.S., Popa L., Robson, C., Shi L., Stano I., Ting E., Vaithyanathan, S., Yang H.(2010) Midas: Integrating public financial data. Proceedings of the 2010 international conference on management of data.

64. Hernandez, M., Ho, M., Koutrika R, Popa L, Stanni S, Vaithyanathan S.(2010) Unleashing the power of public data for dinancial risk measurement, Regulation and governance. IBM research report RJ 10475(A1011-018).

65. Deissenberg, C., Dawid, Van der Hoog S. (2008) EURACE: A Massively parallel agentbased model of the european economy, applied mathematics and computation.

66. Aikman, D., Alessandri, P., Ekland B., Gai P., Kapadia S., Nestia E, Mora N., Sterne G., Wilison M. (2009) Funding liquidity risk in quantitative model of systemic stability. WP372 Bank of England. 
67. Markose, S., Amadeo A., Stephen M. and Yang, J. (2012), "Designing large value payment systems:An agent-based approach", Economics Department University of Essex WP, No. 700. Number 67.

68. Erev, I., Roth A. (1998) Predicting how people play games: reinforcement learning in experimental games with unique, mixed strategy equilibria. American Economic Review. 88: 848-881.

69. Kane, E.(2010) Redefining and Containing Systemic Risk. Mimeo Boston College.

70. Eichengreen B. (2010) Globalization and the Crisis. Institute for Economic Research University of Munich CESifo Forum Journal. 11: 20-24.

71. Segoviano, M., Goodhart C., (2009) Banking stability measures. IMF. 2009; WP 09/04.

72. Mistrulli, P.E.(2011) Assessing financial contagion in the interbank market: Maximum entropy versus observed interbank lending patterns. Journal of Banking \& Finance. 35(5): 11141127.

73. Cont, R., Moussa A., Santos E.(2010) Network structure and systemic risk in banking systems. Available from SSRN: http://ssrn.com/abstract=1733528. Also available from: http://dx.doi.org/10.2139/ssrn.1733528.

74. Craig B, Von Peter G. Interbank tiering and money center banks. 2010. BIS WP 322.

75. Hamilton J D. A new approach to the economic analysis of non stationary time series and business cycle. Econometrica.1989; 57(2): 357-384.

76. Ang A, Bekaert G. How do regimes affect asset allocation. Financial Analysts Journal. 2004; 60: 86-99.

77. Minsky H. The Financial-Instability hypothesis: Capitalist processes and the behavior of the economy. In Kindleberger and Laffargue, editors. Financial Crises. 1982.

78. Adrian T, Brunnermeier M.K. (2009) CoVaR. Federal Reserve Bank of New York Staff Reports. No.348.

79. Acharya V, Pedersen L, Philippon T, Richardson M. Measuring Systemic Risk. Federal Reserve Bank of Cleveland. 2010; WP 1002.

80. Chan-Lau, Jorge A. Regulatory capital charges for too-connected-to-fail institutions: a practical proposal. IMF. 2010 DP 98/10.

81. Huang X, H Zhou, H Zhu. Systemic risk contribution. BIS WP. 2010; 60-3.

82. Segoviano, M., Goodhart C., (2009) Banking stability measures. IMF. 2009; WP 09/04.

83. Tarashev N., Borio,C., Tsatsaronis, K. (2009) The systemic importance of financial institutions. BIS Quarterly Review:75-87. 
84. Gauthier C, Lehar A, Souissi M. (2009) Macroprudential capital requirements and systemic risk. WP; Ottawa: Bank of Canada.

85. Danielsson, J., James, K., Valenzuela M., Zer, I. (2011) Model risk of systemic risk models. London School of Economics. Mimeo.

86. Martinez Jaramillo S., Alexandrova-Kabadjova, B., Bravo-Benitez, B., Solorzano-Margain J.P. (2012) An empirical study of the Mexican banking system's network and its implications for systemic risk. Bank of Mexico. WP 2012-07.

87. Bluhm, M., Krahnen J.P. (2011) Default risk in an interconnected banking system with endogeneous asset markets. Goethe University. 2011; mimeo.

88. Kirman, A., Markose, S., Giansante, S., Pin P. (2007) Marginal contribution, reciprocity, and equity in segregated groups: bounded rationality and self-organization in social networks. Journal of Economic Dynamics and Control. 31: 2085-2107.

89. Myerson, R. (1977) Graphs and cooperation in games. Mathematical Operation Research, $2: 225-229$.

90. Wang, Y., Chakrabarti D., Wang, C., Faloutsos, C. (2003) Epidemic spreading in real network: an eigenvalue viewpoint. Reliable Distributed Systems, IEEE Symposium.

91. Giakkoupis , G., A. Gionis, E. Terzi, and Tsaparas, P. (2011) "Models and Algorithms for Network Immunization," University of Helsinki, Mimeo.

92. Gai, P., Haldane,A., Kapadia S.(2010) Complexity, concentration and contagion. Journal of Monetary Economics. 2010; 58: 453-70.

93. Winter, S.(2010) Testimony Submitted to the Congress of the United States, House Science and Technology Committee, June 20, 2010. 